\title{
State-of-the-art piezoelectric transformer-based switch mode power supplies
}

\author{
Ekhtiari, Marzieh; Zhang, Zhe; Andersen, Michael A. E.
}

\section{Published in:}

Proceedings of IECON 2014

Link to article, DOI:

10.1109/IECON.2014.7049271

Publication date:

2014

Document Version

Early version, also known as pre-print

Link back to DTU Orbit

Citation (APA):

Ekhtiari, M., Zhang, Z., \& Andersen, M. A. E. (2014). State-of-the-art piezoelectric transformer-based switch mode power supplies. In Proceedings of IECON 2014 (pp. 5072-5078). IEEE.

https://doi.org/10.1109/IECON.2014.7049271

\section{General rights}

Copyright and moral rights for the publications made accessible in the public portal are retained by the authors and/or other copyright owners and it is a condition of accessing publications that users recognise and abide by the legal requirements associated with these rights.

- Users may download and print one copy of any publication from the public portal for the purpose of private study or research.

- You may not further distribute the material or use it for any profit-making activity or commercial gain

- You may freely distribute the URL identifying the publication in the public portal

If you believe that this document breaches copyright please contact us providing details, and we will remove access to the work immediately and investigate your claim. 


\title{
State-of-the-art piezoelectric transformer-based switch mode power supplies
}

\author{
Marzieh Ekhtiari, Zhe Zhang, Michael A. E. Andersen \\ DTU Elektro \\ Technical University of Denmark \\ Kgs. Lyngby, Denmark \\ maekh@elektro.dtu.dk, zz@elektro.dtu.dk, ma@elektro.dtu.dk
}

\begin{abstract}
Inductorless switch mode power supplies based on piezoelectric transformers are used to replace conventional transformers in high power density switch mode power supplies. Even though piezoelectric-based converters exhibit a high degree of nonlinearity, it is desirable to use piezoelectric transformers due to their smaller size, lighter weight, lower electromagnetic interference, higher power density, higher efficiency, and lower cost. Moreover, PTs allow converters to operate in high switching frequencies and by obtaining soft switching condition, switching losses will decrease. This paper discusses power supplies with the trend evaluation of piezoelectric transformer-based converter topologies and control methods. The challenges of piezoelectric transformers regarding soft switching capability and nonlinearity are addressed. This paper can be used as a guideline for choosing a proper topology of piezoelectric-based switch mode power supply and a control method for the required application.
\end{abstract}

Keywords-Piezoelectric transformer; Half-bridge topology; Bi-directional control method; Zero voltage switching

\section{INTRODUCTION}

Development within piezoelectric transformer (PT)-based switch mode power supplies (SMPS) has been increasing with regards to smaller size, lighter weight, lower cost, lower electromagnetic interference (EMI), higher power density, and higher efficiency. Furthermore, the manufacturing process of PT can be simpler than electromagnetic transformers, since any winding or core assembling are not required. The objective of this research is to summarize applied converter (specifically SMPS) topologies, employed control methods, reduction of switching losses and challenges due to the stabilization of PT's operation.

This paper explores PT-based converters and topologies that have been proposed for different applications. The primary focus of this paper is to review the topologies and control methods in PT-based SMPS. The study starts with a brief explanation of PT behavior in SMPS by its constraints and requirements. Thereafter, investigation has been conducted on the essentials of zero voltage switching (ZVS) in these type of

This work is funded by "The Danish National Advanced Technology Foundation" with collaboration of Noliac A/S, Siemens Healthcare and IPU as partners. converters and attempts to define ZVS regions or factors for gaining desired performance of PTs inside the circuit. Comparison has been made between converter topologies together with the trend of their applications.

Examination was done on control methods used for increasing performance of converters by introducing the necessity of closed loop control. Closed loop control is indispensable for compensating influence of parameters such as frequency and temperature, in order to have stable operation of PT and consequently accurate performance of the converter. Bi-directional converters are targeted in this paper but most prior art used uni-directional converters; therefore, additional control methods were added into the scope. The control methods reviewed include: phase shift control, self-oscillating, burst mode and double feedback loop, etc.

The paper is organized as follows. In section II the state-ofthe-art piezoelectric transformer-based SMPS is reviewed in terms of principles of PTs, their soft switching ability, uni-directional converter topologies, and control methods. In Section III, new challenges in the area of PT-based SMPS will be introduced. These are considered to be starting points for further research. Finally, conclusion is presented in section IV.

\section{PRIOR ART}

\section{A. PTs in SMPS}

Employment of PTs has become popular since it can replace magnetic and reactive components in both resonant and traditional magnetic transformer based converters. The switching frequency may be either above or below the resonant frequency of a PT. PTs can behave as inductors in a limited range above each resonant frequency. Furthermore, when PTs are operated slightly above resonant frequency, the series resonant network becomes inductive and provides sufficient resonating energy for charging its input capacitor. This results in achieving ZVS. Therefore, PTs can be replacements of resonant circuits in power converters.

The operating principle of the PT is based on electromechanical energy conversion. There is electromechanical coupling between the primary and secondary 


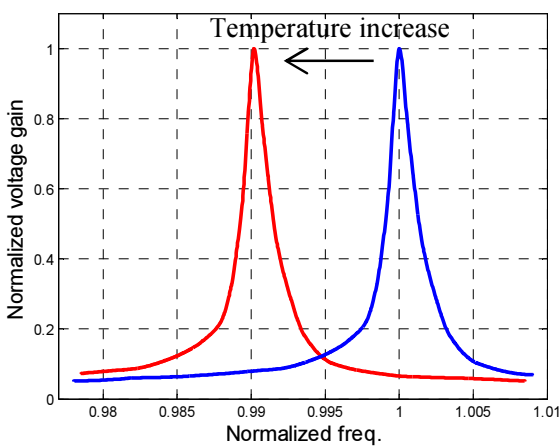

Fig. 1. Gain curve before and after a frequency shift from increase in temperature.

sides inside PTs, where the primary acts as a piezoelectric actuator and the secondary acts as a piezoelectric transducer. Transmitted energy ratio in PTs cannot exceed 95\% due to piezoelectric material losses [1]. PTs are frequency-, load- and temperature- dependent $[2,3,4,5]$. This fact influences their voltage gain and efficiency. Figs. 1 and 2 retrieved from [5] show variations of voltage gain due to temperature increment. Conclusively, a positive temperature change can result in both decrease of the PT gain and shift in its resonant frequency.

Some relationships between key parameters of PTs have been shown by generic closed-form equations [2], which can be used as analytical trade-off for design optimization of PTs in a required application. However, there are several production related parameters, e.g. size, oven temperature, polarization and electrode material, which bring some challenges to PT design. Furthermore, utilization of finite element method (FEM) software, e.g. COMSOL, gives a degree of freedom in PT designs for more considerations regarding application and fabrication [6].

PTs could be driven by either sine wave or square wave, while less reactive components are required for generating square wave [7]. PTs behave like high Q band pass filters; therefore they filter the input square waveform to generate sine wave resonant current and output voltage, which is mainly considered as fundamental signal of the input square wave. However, higher order resonant signals are also generated in the circuit which affects performance of the converter $[8,9]$.

\section{B. Soft Switching operation and constraints}

PT-based converters could benefit from soft switching due to

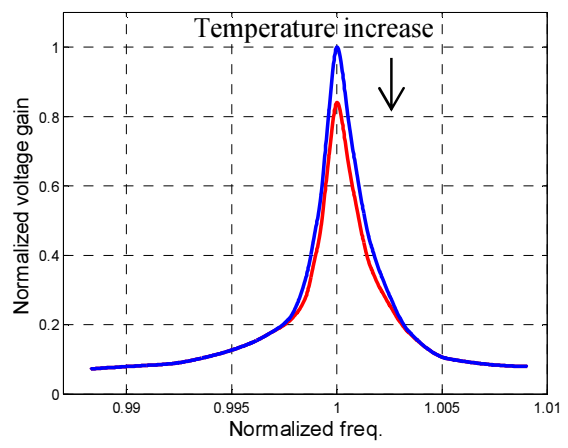

Fig. 2. Gain curve before and after an increase in loss resistance from an increase in temperature.

significantly diminishing switching losses and stresses. Otherwise, energy stored in the input capacitor of PTs would be dissipated in MOSFETs and would cause hard switching. Researches show considerable increase of efficiency by achieving soft switching, e.g. efficiency has been increased from $70 \%$ to $83 \%$ by soft switching [10].

Providing adequate dead time in order to deliver sufficient energy for charging and discharging the input capacitance of PTs is required for achieving ZVS [11], besides preventing shoot through. This means that the design of PTs and driving circuits must be performed together in order to ensure ZVS.

Several attempts have been made to analyze the inherent soft switching capability of PTs by estimating [12] and providing analytical model for calculating [13] the load and the frequency boundaries. The obtainable ZVS region of PTs is very small regarding load and frequency [13]. Moreover, maximum obtainable soft switching has been derived in a simple relation [14] in order to design PTs under the matched load condition. This expression relates ZVS to the input and output capacitors of PTs in addition to efficiency (1). The equation demonstrates validating functionality of ZVS, with the design parameter of $V_{p}^{\prime}$ which is known as the ZVS factor.

$$
V_{p}^{\prime}=\left(0.304 \frac{1}{n^{2}} \frac{C_{d 2}}{C_{d 1}}+0.538\right)(0.585 \eta+0.414)
$$

Where $C_{d 1}$ and $C_{d 2}$ are input and output electrode capacitances of PT, $n=\frac{1}{N}$ is effective turn ratio of PT shown in Fig. 5, and $\eta$ is PT efficiency.
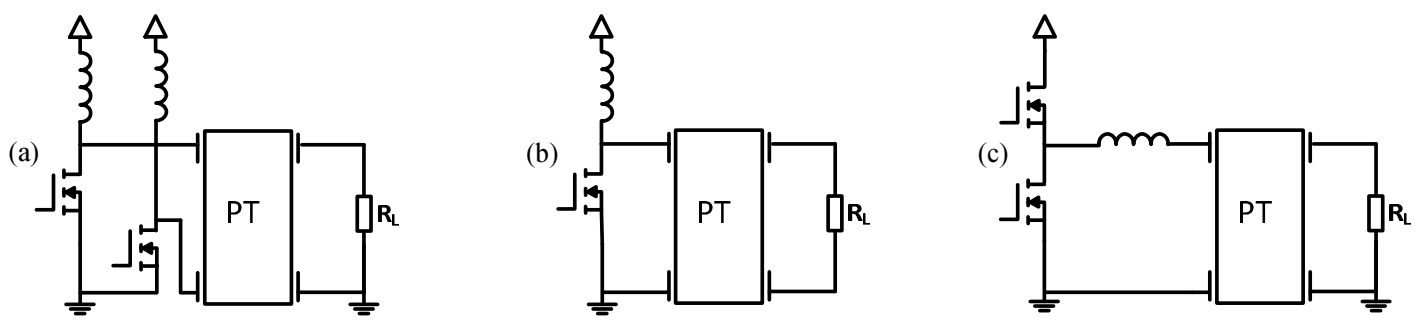

Fig. 3. Most popular converter topologies for driving PT: (a) Push-pull topology, (b) Class-E, (c) Half-bridge. 


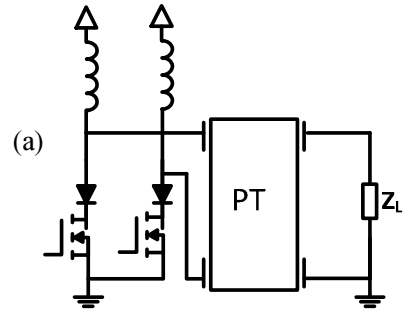

Fig. 4. Typical topologies for driving PT inverter. (b) Voltage-source resonant inverter (b)

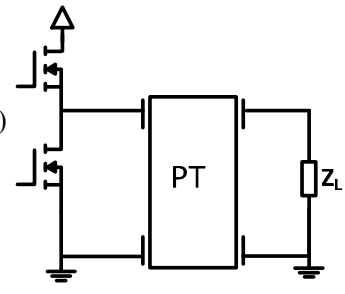

(a) Current-source resonant

\section{Uni-directional converter topologies}

As one of the initial researches on converter topologies, the dissertation [8] compares the performance of three different topologies of PT converters: half-bridge, single-ended multiresonant (SE-MR) and single-ended quasi-resonant (SE-QR) PT converters. The comparison shows that DC/AC voltage gain for half-bridge and SE-MR can feasibly be below unity, while it is naturally above unity for SE-QR. Therefore, SE-MR and half-bridge can be used in step-down applications. The SE-QR is suitable for step-up applications and cost effective by having one switch and one inductor. Although half-bridge topology has more complicated structure and components than other alternatives, it has the advantage of greater efficiency and less generated noise.

Several standard topologies, i.e. push-pull, half-bridge and class-E, are investigated in $[7,15,16,17,18]$. Fig. 3 shows the most popular topologies for PT-based converters.

Push-pull topology has been recommended for step-up applications compared to half-bridge for reasons of simpler control and higher step-up ratio [7, 9]. Resonant push-pull drivers have been applied for continuous energy transferring with amplitude modulation for the first time [15] with a rough efficiency of $70 \%$. The design benefits from two additional inductors. Compared to half-bridge topology, push-pull topology has less dissipation loss generated within the PT due to less filtration of input voltage harmonics [15]; therefore, there are more spurious modes in the resonant current and consequently output voltage.

Class-E and half-bridge topologies both are appropriate for step-down applications. Comparison of PT-based resonant topologies for step-down applications is performed [19], which result in priority for implementation of class-E compared to half-bridge due to better EMI suppression, lower switch current peaks, and larger control bandwidth. On the contrary, halfbridge topology shows better performance in high power levels compared to class-E $[9,19]$.

Some topologies have been identified as using PTs in parallel or series resonance for high-voltage power supplies [4]. Current source inverters have been used for supplying PTs in parallel resonance. The advantages to this are having less switching losses and voltage spikes compared to magnetic transformers, while the disadvantages are having unsatisfactory cost and size as a result of using two inductors for input current

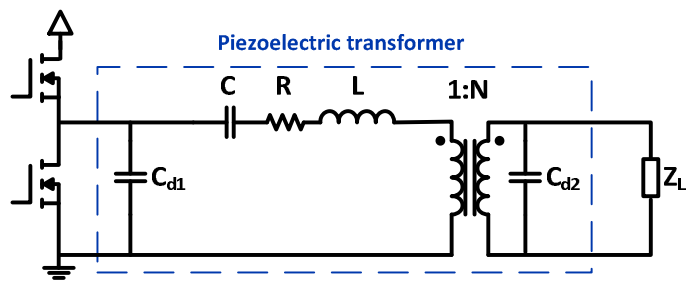

Fig. 5. Schematic diagram of the inductorless half-bridge topology and the Mason's lumped parameter model of PT.

filtrations. Half-bridge topology has been utilized for the resonating of PTs around series resonance which leads to simpler and cheaper drivers. In both cases, PTs have been supplied by square wave form. Despite input current or voltage driving method, PTs behave as a voltage supply for the load. Fig. 4 shows these two types of topologies.

Nevertheless, there have been some prior efforts by utilizing one or several magnetic devices, i.e. inductors, for achieving ZVS in converters [8, 15, 20, 21]. The usage of one or more magnetic devices has been done in resonant converters by placing an inductor in series with a PT in the half-bridge topology in order to pump sufficient current into the input capacitor of the PT during dead time. With these approaches, full advantage of PTs could not be achieved and resulted in extra expense, size and effect of EMI in power supplies. Therefore, PTs should be used with inductorless converters in order to have effective reduction of cost and size [3, 12, 22].

Inductorless PT-based resonant converter topologies were analyzed for both AC output and DC output forms regarding obtaining ZVS [23]. Five different topologies were appraised for standard PT equivalent circuit. That research shows that in case of having optional dead time and frequency, achieving ZVS will depend on parameters, i.e. load condition, inverse of efficiency at the load condition and PT capacitor ratio. Finally, this resulted in ZVS-achievable criteria by standard equivalent circuit which is valid for any type of PT.

A method based on bootstrap method has been proposed in [24] for summation of several PT sub-converter outputs as a solution for non-isolated converters. Fig. 5 shows a block diagram of inductorless half-bridge PT driver.

Inductorless half-bridge topology has been employed for first ballast circuits with high efficiency and cost effectiveness for driving linear fluorescent lamp by utilization of radial vibration mode PTs [25]. In [14], this topology has been applied and a simple expression of soft switching capability has been revealed by empirical deriving of the ZVS factor. However, the shortcoming is that this factor is valid only when the load is matched.

\section{Control methods}

Temperature and load fluctuations cause changes in the operating point of PTs. Temperature increase is inevitable due 


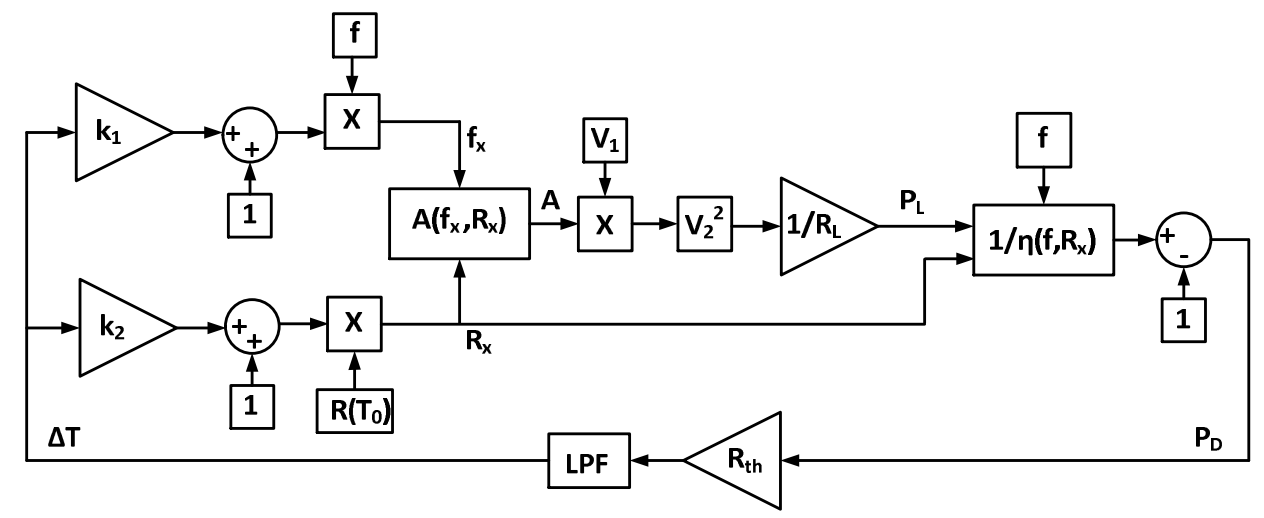

Fig. 6 Thermo-electric model of a PT with the effect of self-heating. Fitted parameters from measurements: $\boldsymbol{K}_{\mathbf{1}}, \boldsymbol{K}_{\mathbf{2}}$ : constant and $\boldsymbol{R}_{\boldsymbol{t h}}$ : absolute thermal resistance to surroundings. $\boldsymbol{f}$ : applied frequency, $\boldsymbol{V}_{\mathbf{1}}$ and $\boldsymbol{V}_{\mathbf{2}}$ input and output voltages $\boldsymbol{f}_{\boldsymbol{x}}$ : shifted frequency, $\boldsymbol{R}_{\boldsymbol{x}}$ : temperature dependent loss resistor, $\boldsymbol{R}_{\boldsymbol{L}}$ : load resistance, $\boldsymbol{A}\left(\boldsymbol{f}_{\boldsymbol{x}}, \boldsymbol{R}_{\boldsymbol{x}}\right)$ : temperature dependent gain, $\boldsymbol{T}_{\mathbf{0}}$ : ambient temperature, $\Delta \boldsymbol{T}$ : temperature change.

to power losses, while conversely there will be a decrease of mechanical quality factor in the PT, which turns into selfheating $[5,26]$. Moreover, a rise in the temperature causes a decrease of resonant frequency. Therefore, a driver could easily shift out of the ZVS region or lead to a lower output voltage and efficiency. A valuable thermo-electric model has been provided in [5] and demonstrates nonlinearities. Fig. 6 shows a block diagram representing this thermo-electric model.

Several attempts have been made to apply control methods for PT-based converters. PTs exhibit a considerably narrow operating frequency range regarding their high quality factor, which brings challenges for obtaining soft switching and appreciable efficiency. However, keeping operating frequency in a proper point which is slightly above resonant frequency is hard to achieve by open loop. As a consequence, closed loop control is vital for maintaining PT operation at optimum point and desirable efficiency of drivers.
Presently, closed loop controls are being performed by measuring phase difference between resonant current and switching signal for the purpose of adjusting the switching frequency to the optimum value to ensure ZVS and achieve maximum possible efficiency of PTs [4, 27]. Closed loop control strategies allowing ZVS operation of converter have been suggested in [27, 28, 29]. Self-oscillating controls have been used in PT-based converters [30, 31] besides extensively using them in class-D amplifiers $[32,33,34]$ as well as in DC-DC converters [35]. Self-oscillating control loops are used for the first time in inductorless topology on top of soft switching PTs in [36]; this shows the concept of beneficial utilization of self-oscillating loops in burst-mode controls, which are also known as quantum-mode controls since they have fast response in tracking resonant frequency at startup.

PT-based half-bridge drivers were used in [37] by utilizing burst mode control technology which has brought a $14 \%$ efficiency increase compared to the magnetic transformer-

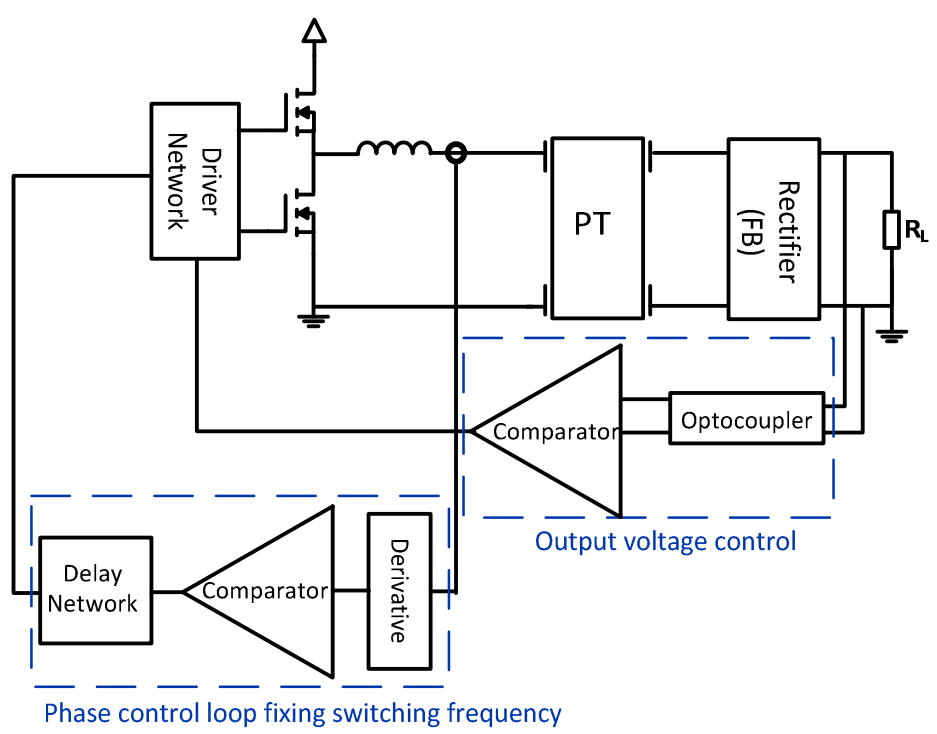

Figure 7: Topology with two feedback loops: resonant current phase and voltage control. 


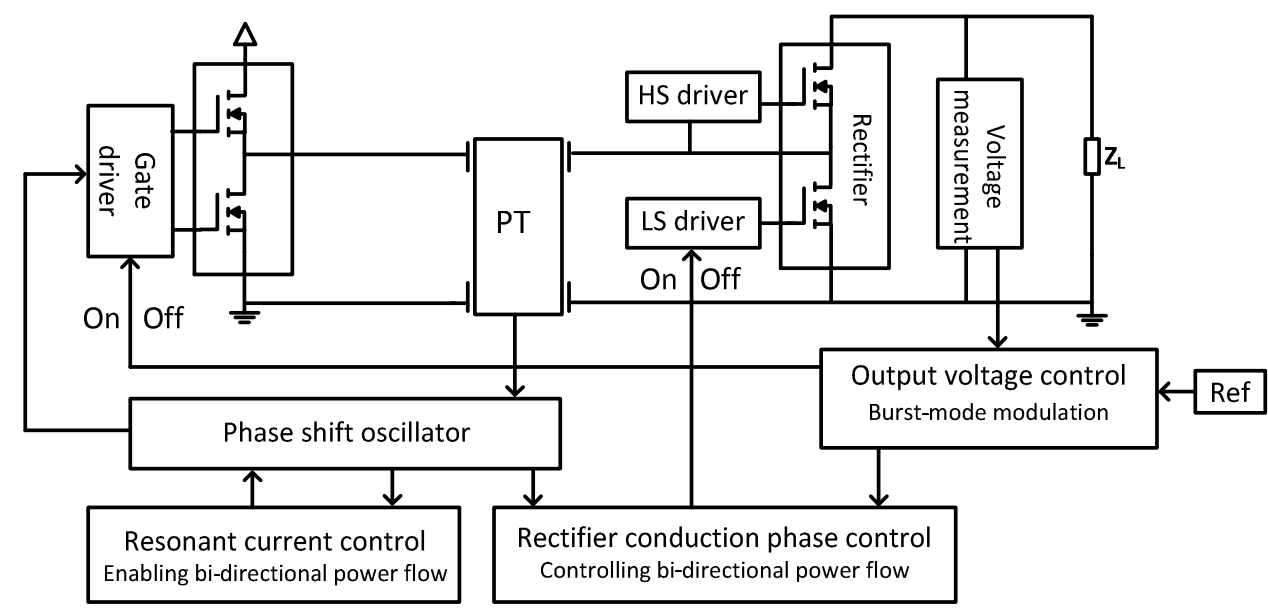

Fig. 8. Function block diagram of the bi-directional control method

based counterparts. Additionally, it has been demonstrated that $41 \%$ loss reduction has been achieved plus considerable improvement in EMI in the frequency range of above $1 \mathrm{MHz}$.

Double feedback loops have been implemented in PT-based DC/DC drivers [21]. One loop using the phase control method for frequency adjusting to obtain ZVS and maximum gain / efficiency, and the other loop for output regulation. With this proposed method, output voltage can be reached quickly. The block diagram of the driver is shown in Fig.7. The topology applied uses an inductor.

An inductorless driver has been implemented in [38] by taking advantage of previous double-closed loops with the combination of burst mode control technology.

\section{E. Bi-directional control method}

Bi-directional PT-based power converters have been implemented for dielectric electro active polymers (DEAP) actuator as load [11, 39]. Phase shift controls were employed in order to avoid the use of two different PTs for achieving ZVS in both forward and reverse energy flow. Experiments substantiate the claim of bi-directional power converters with active phase shift controls and utilization of just one PT. Fig.8 shows a block diagram of bi-directional control method for the inductorless half-bridge topology [9, $36,39]$.

\section{F. Comparison and examples}

Table I shows some examples of investigated topologies with claims of efficiency and output power level and Table II shows an overview comparison of the most popular PT-based converter topologies from prior art study.

\section{NEW CHALLANGES}

PTs use electromechanical coupling between the primary and secondary sides compared to conventional transformers that use electromagnetic coupling. This introduces PTs as applicable candidates for applications which have a high sensitivity to electromagnetic interference, e.g. magnetic resonance imaging (MRI) scanners. Therefore, PTs with nonmagnetic drivers may be able to work in high electromagnetic fields, e.g. 7 Tesla.

This section proposes challenges for PT-based power drivers and possible solutions based on the state-of-the-art technology for addressing these challenges.

\section{A. Challenges for PT}

Challenges for the design of PTs are:

- To increase power density: results in higher power transmission into the output of converter. It is limited by design and production factors.

- To raise power transmission capability: leads to have simpler converters and control techniques by utilizing as few PT as possible.

- To combine PTs, creating new techniques for increased power through output: e.g. a method of connecting PTbased converters for the output voltage summation is proposed in [24]. Suggestion for combination methods depends on the application and it is important to avoid complexity in circuit design.

TABLE I. Efficiency and power level examples

\begin{tabular}{|l|c|c|c|c|c|c|}
\hline Topology & Push Pull & \multicolumn{2}{|c|}{ Class E } & \multicolumn{3}{|c|}{$\begin{array}{c}\text { Half-bridge } \\
\text { Inductorless }\end{array}$} \\
\hline Efficiency(\%) & 70 & 82.4 & 70.5 & 58.5 & 90 & 90 \\
\hline Power[W] & 2 & 3.6 & 3.6 & 3.6 & 32 & 6.5 \\
\hline Reference & {$[15]$} & {$[19]$} & {$[19]$} & {$[37]$} & {$[25]$} & {$[28]$} \\
\hline
\end{tabular}


TABLE II. Comparison of most popular PT-based SMPS topologies

\begin{tabular}{|l|c|c|c|c|c|}
\hline Topology & Application & Control & Efficiency & Power level & EMI \\
\hline Push-Pull & $\begin{array}{c}\text { Step-up } \\
\text { Higher ratio than half-bridge [7] }\end{array}$ & $\begin{array}{c}\text { Output current } \\
\text { control [16] }\end{array}$ & $\begin{array}{c}\text { 86\% [16] } \\
\text { (Inductor) }\end{array}$ & Low \\
\hline Class $\boldsymbol{E}$ & $\begin{array}{c}\text { Step-down } \\
\text { Power application [7] }\end{array}$ & PLL & $\begin{array}{c}\text { 82.4\% } \\
{[19]}\end{array}$ & High [17] & $\begin{array}{c}\text { Yes } \\
\text { (Inductor) }\end{array}$ \\
\hline $\begin{array}{l}\text { Class D/ } \\
\text { Half-bridge }\end{array}$ & $\begin{array}{c}\text { Step-down } \\
\text { Power application [7] }\end{array}$ & $\begin{array}{c}\text { Phase shift } \\
\text { Ford conduction } \\
\text { Burst mode [37] }\end{array}$ & 90\% [28] & $\begin{array}{c}\text { Very high } \\
{[9,19]}\end{array}$ & (Inductorless) \\
\hline
\end{tabular}

\section{B. Challenges in power stages}

Energy recovery through bi-directional current flow is critical for achieving high driver efficiency. As energy is directed back from the output side, the properties of the PT change dramatically, e.g. soft switching ability. Therefore achievable ZVS is required for both forward and reverse power flow directions. This imposes strict requirements on the driver design. The driver should allow for suitable control of the PT, and techniques for obtaining high efficiency and compact converter which these call for new solutions. If the load is capacitive piezoelectric actuator, bi-directional current flow requires advanced control schemes to allow precise control of the capacitive load. According to the prior art, half-bridge topology and the self-oscillating control loop based on the phase shift control method can be selected for resolving this challenge. Furthermore, in case of using several PTs for increasing the demanded output power, more complex control loops is required to combine converters together.

\section{CONCLUSION}

In this paper, the principle of state-of-the-art PT-based SMPS has been studied with the aim of appraising important considerations in the design of converters. In the prior art section, major factors in PT design have been reviewed, as well as the soft switching capability of PTs which allows obtaining ZVS in the converter and a decrease of switching losses. The main focus of this paper has been researching power stage topologies and control methods used in prior art and their applications. Research in this paper shows inevitable implementation of one or more control loops for better performance of PTs and converters, and the correlation between efficiency, losses, temperature and frequency.

Furthermore, new challenges for future research are introduced both in PT design and in power stages, with a guide to topology and control method selection.

\section{REFERENCES}

[1] V. Loyau, Y. Liu, F. Costa, "Analysis of the heat dissipated by losses in a piezoelectric transformer," IEEE Transactions on Ultrasonics, Ferroelectrics, and Frequency Control, vol. 56, no. 8, 2009, pp. 1745-52.

[2] G. Ivensky, I. Zafrany, and S. B. Yaakov, "Generic operational characteristics of piezoelectric transformers," IEEE Transaction on Power Electronics, vol. 17, no. 6, 2002, pp. 1049-1057.

[3] E. L. Horsley, M. P. Foster, and D. A. Stone. "State-of-the-art piezoelectric transformer technology." In Power Electronics and Applications, 2007 European Conference on, IEEE, pp. 1-10, 2007.

[4] J. M. Alonso, C. Ordiz, M. A. D. Costa, J. Ribas, and J. Cardesin, "High-voltage power supply for Ozone generation based on piezoelectric transformer", IEEE Transaction On Industry Applications, vol. 45, no. 4, 2009, pp. 1513-1523.

[5] T. Andersen, M. A. E. Andersen, O. C. Thomsen, M. P. Foster, and D. A. Stone, "Nonlinear effects in piezoelectric transformers explained by thermal-electric model based on a hypothesis of self-heating," IECON , 38th Annual Conference on IEEE Industrial Electronics Society, 2012, pp. 596-601.

[6] T. Andersen, M. A. E. Andersen, and O.C. Thomsen, "Simulation of piezoelectric transformers with COMSOL", COMSOL conference, 2012 .

[7] A. Carazo, "50 years of piezoelectric transformers. Trends In the technology," Materials research society, 2004.

[8] C. Lin, "Design and analysis of piezoelectric transformer converters," $\mathrm{Ph}$.D. dissetation, Virginia Polytechnic Institute and State University, 1997.

[9] M. S. Rødaard, "Piezoelectric transformer based power converters; design and control," Ph.D. thesis, Technical University of Denmark, 2012 .

[10] Anita M. Flynn, Seth R. Sandres, "Fundamental limits on energy transfer and circuit considerations for piezoelectric transformers", IEEE Transactions on Power Electronics, vol. 17, no.1, 2002, pp. 8-14.

[11] T. Andersen, "Piezoelectric transformer based power supply for dielectric electro active polymers," PhD Thesis, 2012, Technical Univesity of Denmark.

[12] S. Bronstein, S. Ben-Yaakov, "Design considerations for achieving ZVS in a half bridge inverter that drives a piezoelectric transformer with no series inductor," Power Electronics Specialists Conference, PESC 02, vol. 2, 2002, pp. 585-590.

[13] E. Horsley, N. Nguyen-Quang, M. P. Foster, and D. A. Stone, "Achieving ZVS in inductor-less half-bridge piezoelectric transformer based resonant converters," 2009 International Conference on Power Electronics and Drive Systems, PEDS 2009, pp. 446-451.

[14] M. S. Rødgaard, T. Andersen, and M. A. E. Andersen, "Empiric analysis of zero voltage switching in piezoelectric transformer based resonant converters," Power Electronics Machines and Drivers Conference, PEMD 2012, pp. 1-6. 
[15] H. Schwarzmann, T. Erlbacher, A. J. Bauer, H. Ryssel, and L. Frey, "Amplitude modulated resonant push-pull driver for piezoelectric transformers in switching power applications," $7^{\text {th }}$ International Conference on Integrated Power Electronics Systems, CIPS, 2012, pp. 15 .

[16] M. Shoyama, K. Horikoshi, T. Ninomiya, T. Zaitsu, "Sready-state characteristics of the push-pull piezoelectric inverter," Power Electrnics Specialists Conference, PESC, $28^{\text {th }}$ Annual IEEE, vol. 1, 1997, pp.715721.

[17] F. E. Bisogno, S. Nittayarumphong, M. Radecker, A. V. Carazo, and R. N. do Prado, "A line power-supply for LED lighting using piezoelectric transformers in class-E topology," proceeding of: Power Electronics and Motion Control Conference, IPEMC 2006, vol. 2, 2006.

[18] C. H. Lin, and Y. C. Chen, "Design of class-E backlight module incorporating piezoelectric transformer," IEEE International Symposium on Circuits and Systems, ISCAS, vol. 4, 2005, pp. 3655-3659.

[19] F. E. Bisogno, M. Radecker, A. Knoll, A.V. Carazo, A Riedlhammer, G. Deboy, N. Norvez, and J.M. Pacas, "Comparison of resonant topologies for step-down applications using piezoelectric transformers," Power Electronics Specialists Conference, PESC 04, IEEE $35^{\text {th }}$ Annual, vol. 4, 2004, pp. 2662-2667.

[20] Choi, Sungjin, Taeil Kim, and Bo H. Cho. "Design of half-bridge piezotransformer converters in the AC adapter applications." In Twentieth Annual IEEE Applied Power Electronics Conference and Exposition, 2005, pp. 244-248.

[21] J. Diaz, J. A. Martin-Ramos, M. J. Prieto, and F. Nuno, "A doubleclosed loop DC/DC converter based on a piezoelectric transformer,", Applied Power Electronics Conference and Exposition, APEC '04. Nineteenth Annual IEEE, vol. 3, 2004, pp. 1423-1428.

[22] M. Sanz, P. Alou, R. Prieto, J. Cobos, and J. Uceda, "Comparison of different alternatives to drive piezoelectric transformers," in Applied Power Electronics Conference and Exposition, APEC 2002. Seventeenth Annual IEEE, vol. 1, 2002, pp. 358-364.

[23] E. L. Horsley, A. V. Carazo, N. N. Quang, M. P. Foster, and D. A Stone, "Analysis of inductorless zero-voltage-switching piezoelectric transformer-based converters," IEEE Transactions on Power Electronics, vol. 27, no. 5, 2012, pp. 2471-2483.

[24] Y. Yuanmao, K. W. Eric Cheng, and Kai Ding, "A novel method for connecting multiple piezoelectric transformer converters and its circuit application," IEEE Transaction on Power Electronics, vol. 27, no.4, 2012, pp. 1926-1935.

[25] R. L. Lin, F. C. Lee, E. M. Baker, and D. Y. Chen, "Inductor-less piezoelectric transformer electronic ballast for linear fluorescent lamp," Applied Power Electronics Conference, APEC 2001, Sixteenth Annual IEEE, vol. 2, 2001, pp. 664-669.

[26] X. Chu, J. Wu, Z. Xu, and L. Li, "Experiment research on multilayer piezoelectric transformer," Symposium on Piezoelectricity, Acoustic Waves, and Device Applications,SPAWDA, 2008, pp. 524-527.

[27] J. M. Alonso, C. Ordiz, M. A. Dalla, "A novel control method for piezoelectric-transformer based power supplies assuring zero-voltageswitching Operation," IEEE Transaction on Industrial Electronics, vol. 55, no. 3, 2008, pp. 1085-1089.

[28] M. S. Rødgaard, M. Weirich, M. A. E. Andersen, "Forward conduction mode controlled piezoelectric transformer-based PFC LED drive," IEEE Transactions on Power Electronics, vol. 28, no. 10, 2013, pp. 48414849 .

[29] S. Nakashima, T. Ninomiya, H. Ogasawara, H. Kakehashi, "Piezoelectric-transformer inverter with maximum-efficiency tracking and dimming control," Applied Power electronics Conference and Exposition, APEC 2002, Seveteenth Annual IEEE, vol.2, pp. 918-923, 2002.

[30] J. Díaz, F. Nuño, M. J. prieto, J. A. Martin-Ramos, "Closing a second feedback loop in a DC-DC converter based on a piezoelectric transformer," IEEE Transaction on Power Electronics, vol. 22, no. 6, 2007, pp. 2195-2201.

[31] J. Díaz, F. Nuño, M. prieto,, "Achieving ZVS in inductor-less halfbridge piezoelectric transformer based resonant converters," 2009 International Conference on Power Electronics and Drive Systems, PEDS 2009, pp. 446-451.
[32] M. A. E. Andersen, "Efficient audio power amplification-challenges," International Conference Audio Engineering Society, AES 2005, pp. 110 .

[33] M. Høyerby and M. A. E. Andersen, "Carrier distortion in hysteretic self-oscillating class-D audio power amplifers: Analysis and optimization," IEEE Transactions on Power Electronics, vol. 24, no. 3, 2009, pp. 714-729.

[34] B. Putzeys, "Simple self-oscillating class-D amplifier with full output filter control," in 118th AES Convention, Barcelona, Spain, 2005.

[35] Y. Wen, O. Trescases, "Analysis and comparision of frequency stabilization loops in self-oscillating current mode DC-DC converters," IEEE Transaction on Power Electronics, vol. 28, no. 10, 2013, pp. 47534766.

[36] M. S. Rødgaard, M. A. E. Andersen, T. Andersen, and K. Meyer, "Selfoscillating loop based piezoelectric power converter," 2011, US Patent 61/638,883 and 2013, WIPO, WO2013083678-A2

[37] T. Andersen, M. S. Rødgaard, M. A. E. Andersen, O. C. Thomsen, K. P. Lorenzent, C. Mangeot, and A. R. Steenstrup, "Integrated high voltage power supply utilizing burst mode control and its performance impact on dielectric electro active ploymer actuators," 13th International Conference on New Actuators, 2012.

[38] T. Andersen, M. S. Rødgaard, O. C. Thomsen, and M. A. E. Andersen, "Low voltage driven electro active polymer actuator with integrated piezoelectric transformer based driver,", Electroactive Polymer Actuators and Devices (EAPAD), vol. 7976, 2011, pp. 7976-95.

[39] M. A. E. Andersen, K. Meyer, M. Rødgaard, and T. Andersen, "Piezoelectric power converter with bi-directional power transfer," 2011, US Patent 61/567,924 and 2013, WIPO, WO2013083679-A1. 